\title{
Da etnografia multissituada à "plataformizada": aproximações entre antropologia e estudos de plataforma
}

\author{
ÍTALO VINICIUS GONÇALVES \\ Universidade Federal de Minas Gerais, Belo Horizonte, Minas Gerais, Brasil \\ italovinicius@rocketmail.com
}

DOI 10.11606/issn.2316-9133.v29i2pe175274

resumo $\mathrm{O}$ objetivo deste artigo é discutir como as noções de "plataforma" e "plataformização" (da web e do social) podem nos ajudar a rever práticas etnográficas, especialmente aquelas realizadas em contextos online. Argumento que as aproximações dos campos da antropologia e da comunicação social podem trazer impactos positivos às discussões de ambas as áreas. Para isso, apresentarei um breve panorama dos estudos de plataforma de modo a introduzir estas noções. Em seguida, trago algumas destas pesquisas que, propositalmente, se articularam às metodologias etnográficas. A proposta é que elas nos permitam repensar o que chamamos de "campo etnográfico", tal qual a ideia de "etnografia multissituada", considerando seus possíveis desdobramentos ao ser friccionada a essa área de investigação. Conclui-se que, por meio da utilização desses conceitos, nossas teorias e práticas virtuais adquiram novas dinâmicas, contornos e significados.

palavras-chave Plataforma. Plataformização. Etnografia multissituada. Teoria etnográfica.

From multisited to "platform-based" ethnography: approximations between anthropology and platform studies

abstract The article discusses how the notions of "platform" and "platformization" (of the web and the social life) can help to review ethnographic practices, especially those carried out in online context. It argues that the approximations of anthropology and social communication fields can bring positive impacts to the discussions in both fields. It presents a brief overview of platform studies introducing these notions. The article also look at some research deliberately combining the ethnographic method and plataform studies. Doing so, it allow us to rethink what we call "ethnographic field", such as the idea of "multisituated 
ethnography" considering its possible unfolding when rubbed against this research field. It concludes that, through these concepts our theories and virtual practices acquire new dynamics, contours and meanings.

keywords Platform. Platformization. Multi-sited ethnography. Ethnographic theory.

De la etnografía multisituada a la basada en "plataformas": aproximaciones entre antropología y estudios de plataforma

resumen El artículo discute cómo las nociones de "plataforma" y "plataformización" (de la web y lo social) pueden ayudar a revisar las prácticas etnográficas, especialmente las que se llevan a cabo en contextos online. Las aproximaciones de los campos de la antropología y la comunicación social pueden traer impactos positivos a las discusiones en ambas áreas. Por esto, presentaré una breve descripción general de los estudios de plataformas con el fin de introducir estas nociones. A continuación, traigo algunas de estas investigaciones realizadas desde la útil articulación con metodologías etnográficas. La propuesta es que nos ayuden a repensar lo que llamamos el "campo etnográfico", como la idea de "etnografía multisituada" considerando su despliegue cuando se frota contra la noción de la plataformización. Se concluye que, a través de la utilización de estos conceptos, nuestras teorías y prácticas virtuales adquieren nuevas dinámicas, contornos y significados.

palabras clave Plataforma. Plataformización. Etnografía multisituada. Teoría etnográfica.

\section{Situando enredamentos}

Entre 2016 e 2017, fui membro do projeto de Iniciação Científica intitulado "O antropólogo no campo e na rede: o fazer etnográfico em pesquisas de gênero e sexualidade”. O objetivo do trabalho consistia em mapear e analisar bibliografias da área temática de gênero e sexualidade feitas em ambientes digitais a partir da década de 1990, as então chamadas "netnografias", e imersas no que se denominava "estudos da cibercultura" (SEGATA 2008). A tarefa ia além de um mapeamento teórico-conceitual, visando compreender como esse material poderia ter relevância no tensionamento de alguns dos conceitos antropológicos clássicos, como os de "campo", "presença”, "estar lá”, "observação participante" e "autoridade etnográfica", por exemplo.

Surpreendentemente, ou não, concluímos na época que, embora a antropologia viesse se esforçando para compreender essas novas dimensões e dinâmicas da vida social, pouco impacto estava sendo produzido na teoria antropológica clássica, ou, pelo menos, 
pouco se deixava impactar dentro dos programas brasileiros de antropologia, cujas ementas apresentavam diálogos modestos com tais exercícios etnográficos. De forma geral, podemos apontar duas de suas principais razões: uma visível resistência antropológica ao novo contexto de pesquisa, além de uma insuficiência empírica que, efetivamente, se propusesse a implodir as categorias clássicas do trabalho etnográfico.

Se tornou evidente para nós o acirramento de um embate: de um lado, havia uma tradição antropológica que olhava com desconfiança esses novos territórios de pesquisa. Entre as principais alegações, havia uma suposta falta de "autenticidade" do campo, momento em que o virtual foi taxado de "enganoso", recaindo sobre ele a necessidade de comprovação dos dados etnográficos "encontrados" pelas pesquisadoras. "Afinal, a inconsistência ontológica do mundo online ("menos-real") o desabilitaria para realizar etnografias que não tivessem uma âncora offline” (LEWGOY 2009: p.189). A acusação também se estendia à qualidade das relações estabelecidas nesses ambientes. Seja pela suposta falta de "espontaneidade", ou pelos novos arranjos temporais impostos por essas práticas de pesquisa. O desafio era "convencer a própria antropologia da possibilidade de fazer etnografias no ciberespaço" (SEGATA 2008: p.3).

Por outro lado, pesquisas como as de Dantas (2011), Facioli (2013) e Ávila (2014) nos mostravam como a internet poderia, de certa maneira, facilitar nossas relações com os sujeitos de pesquisa. Conforme argumentaram, as preocupações iniciais relativas à espontaneidade de seus interlocutores foram dando lugar a relações mais íntimas quando comparadas às experiências "físicas" de pesquisa. Se, num primeiro momento, Dantas (2011) se viu impossibilitada de acessar narrativas referentes às práticas sexuais de seus interlocutores do sexo masculino em conversas cara a cara, devido à diferença sexual, foi por meio de entrevistas realizadas via $\mathrm{msn}^{1}$ que esses sujeitos se sentiram suficientemente confortáveis para se abrirem emocionalmente com a pesquisadora. Facioli, inclusive, pontua que "Nas etnografias face a face, as conversas também eram passíveis de tomarem outros rumos, mas na rede, questões delicadas, que envolvem a esfera da intimidade, da família, da sexualidade e das relações amorosas podem vir à tona logo nos primeiros minutos de papo" (FACIOLI 2013: p.76).

Outras "facilidades" somavam-se à espontânea abertura emocional dos indivíduos, como a possibilidade de existência de um campo pré-circunscrito, onde o antropólogo encontraria, de antemão, acesso a determinados dados, hábitos e narrativas, antes mesmo de estabelecer qualquer relação em campo (SILVA 2004; FREITAS 2011; BARBOSA 2014; VENCATO 2015). Este seria um dos efeitos da dilatação entre as dimensões privadas e públicas que acompanharam a implementação da web 2.0.

\footnotetext{
${ }^{1} \mathrm{O}$ msn foi uma plataforma de conversas online semelhante ao whatsapp que encerrou suas atividades em 2013
} 
Fato é que, se no momento do projeto ainda havia uma certa busca pela legitimidade das práticas netnográficas, este cenário foi completamente revisto pouco tempo depois. Em 2018, a "algoritmização da vida" se transformou em assunto de bar. Se até então grande parte das pesquisas feitas em campos virtuais (sobretudo, as identificadas no citado projeto de iniciação científica) ainda descreviam esses ambientes numa espécie de replicação do modelo malinowskiano, neste momento já não cabia mais à antropologia tratar o virtual apenas como meio. Nesse momento o seu caráter agentivo e performático passou a ser fator imprescindível na compreensão das configurações dessas esferas sociais, o que é particularmente ilustrado no Brasil pelas eleições de 2018 e o debate em torno do uso das redes sociais.

Portanto, o objetivo deste texto é expandir a teoria etnográfica ao atrelar nossas práticas de pesquisa online ao fenômeno da "plataformização", termo cunhado para designar os entrelaçamentos possíveis entre as diversas ambiências digitais e suas relações com a vida social. Proponho um diálogo entre a teoria antropológica e os estudos de plataforma ao considerar que nossas práticas netnográficas são também experiências plataformizadas, e que tais dimensões não deveriam ser negligenciadas em nossos trabalhos. Se experiências netnográficas foram/são comumente associadas à proposta "multissituada" de Marcus (1995), devido às relações mantidas entre as dimensões off e online, nossa proposição amplia essa noção ao pensar os processos de plataformização que atravessam nossos fenômenos, apresentando novas "escalas" de pesquisa nos termos de Marcus (1995). Para além disso, acredito que tais articulações sejam potentes aos tensionamentos outrora almejados no projeto apresentado. De início, nos caberá entender a origem dos conceitos de "plataforma" e "plataformização da web" e "da vida social”, assim como suas aplicações. Posteriormente, discutiremos de que forma os estudos de plataformas se encoram às práticas etnográficas e como o exercício inverso pode ser bastante fecundo a nossas práticas de pesquisa, ainda que não partam necessariamente dos ambientes digitais.

\section{A plataformização e a exponencialidade do social}

Se no final da década de 90 e começo dos anos 2000 a antropologia ponderava sobre o impacto da cibercultura em suas práticas de pesquisa (GUIMARÃES JUNIOR 2000), agora nossos campos são (ou pelo menos deveriam ser) pensados considerando o fenômeno da "plataformização". Assim, ao olharmos para as plataformas digitais, não apenas percebemos tais ambiências enquanto espaços de comunicação e/ou de sociabilidades, mas também como infraestruturas que configuram e modulam modos de vida, organizações sociais e percepções do real de maneira intercambiável (como veremos mais à frente). Em destaque neste cenário, os algoritmos, via de regra, "ocupam um lugar central nos processos de conhecimento de uma certa realidade, bem como nos processos de tomada de decisão e de gestão dessa mesma 
realidade" (BRUNO 2019), recaindo sobre eles a culpabilização pelas diversas crises políticas atuais, sobretudo no que se refere às interferências nas democracias globais ${ }^{2}$. Seguindo o "repovoamento do social", apontamento feito por Rifiotis (2016) ao considerar a participação das novas estruturas digitais na vida cotidiana, temos como tarefa a captura das parcelas dos processos de fabricação social, cujos fluxos nos ajudam a compreender as dinâmicas de coprodução de entes e tecnicidades, realizadas de modo bastante rizomático, contínuo e exponencial.

Antes de nos concentrarmos sobre as possíveis inflexões que os processos de plataformização podem provocar em nossas práticas etnográficas (online, sobretudo, mas não somente), é necessário saber o que, de fato, é e faz uma plataforma. Segundo Van Dijck, Poell e de Wall (2018: p.4) "uma plataforma online é uma arquitetura projetada para organizar interações entre usuários - não apenas usuários finais, mas também entidades corporativas e órgãos públicos". Portanto, é uma infraestrutura que tem por objetivo controlar e dimensionar o fluxo de dados conforme modelos de negócio particulares. Elas se diferenciam das então tradicionais redes sociais por modularem as práticas e relações de seus usuários através da coleta sistemática de dados e da personalização de seus serviços, baseados em "monitoramentos" e prognósticos comportamentais. Ou seja, ainda que o extinto Orkut pudesse ter algum grau de mediação nas sociabilidades em rede, ele não era capaz de trabalhar a partir dos rastros deixados por seus usuários, e, consequentemente, acabou perdendo espaço por não conseguir se adequar ao tipo de trabalho individualizado proporcionado pelo Facebook, por exemplo ${ }^{3}$.

Por isso, consideremos três de suas principais características: a) intercâmbio de dados entre plataformas por meio das API's (que possibilitam, de fato, um cenário plataformizado); b) centralização/descentralização dos fluxos de fornecimento/produção de dados; c) trabalho algorítmico individualizado ${ }^{4}$.

\footnotetext{
${ }^{2}$ A problematização da "responsabilidade algorítmica" é parte dos estudos de plataforma, que tem por objetivo evidenciar que algoritmos não são coisas dadas, mas frutos de processos técnico-culturais. Para essa discussão, ver Taina Bucher (2018).

${ }^{3}$ O Orkut foi a principal rede social de domínio da Google, funcionou de 2004 a 2014, e tinha mais de 29 milhões de usuários só no Brasil. Em comparação, atualmente, o Facebook possui mais de 120 milhões de usuários ativos no Brasil.

${ }^{4}$ Interface de Programação de Aplicações (API na sigla em inglês), denomina um modo de estruturação de programas computacionais que permite sua interoperabilidade com outros sistemas. Por meio de uma API, um programa de computador pode ser projetado de modo a empacotar determinadas funções e recursos de dados para que sejam acessados por um programa externo. No contexto da computação distribuída e da plataformização da web, APIs permitem a disponibilidade pública ou comercial de serviços computacionais e dados. Na prática, significa que milhares de indivíduos ou empresas podem usar de forma automática e padronizada, geralmente por pagamento baseado em demanda, os serviços digitais e dados de uma empresa fornecedora. (SILVA et al. 2020: p.30)
} 
D’Andréa (2020), por sua vez, identifica cinco principais dimensões estruturais: a) datificação e algoritmos, cujos processos baseiam-se em identificar e prever os comportamentos dos usuários a partir de suas práticas nas plataformas e por meio de trabalho algorítmico; b) infraestrutura, pensando a condição material de armazenamento desses dados, como também a própria estrutura das redes e seus pontos de encontro; c) modelos de negócio, referentes aos usos comerciais da datificação e dos processos algorítmicos; d) governança, sendo o "conjunto heterogêneo de mecanismos e práticas de ordem técnica, política, jurídica e comercial que regulam seu funcionamento” (D’NDRÉA 2020: p.24); e, por fim, e) práticas e affordances, relativos aos usos individuais e coletivos das plataformas, sobretudo aos modos imprevistos destas ações.

Ainda, o modelo de plataforma é resultante dos investimentos feitos pelas grandes empresas (estadunidenses, sobretudo) para promover um novo sentido àquilo que conhecíamos por internet. Enquanto se saudava a grande abertura democrática promovida pela web 2.0 em torno das noções de "cultura participativa" (JENKINS 2006), "sabedoria das multidões” e "inteligência coletiva” (D'ANDRÉA 2020: p.9), as fronteiras entre o público e privado eram cada vez mais dissipadas. Embora na primeira década dos anos 2000 a internet fosse vista enquanto espaço potencial de democratização popular, seja no acesso à informação ou na promoção de relações em nível global, esse cenário se inverte uma década depois, principalmente após o escândalo da Cambridge Analytica, evento cuja notoriedade global colocou ainda mais no centro da discussão os possíveis efeitos de um mundo plataformizado ${ }^{5}$. Portanto, os estudos de plataforma surgem por volta de 2010, num cenário de virada crítica "da sedutora retórica da colaboração sobre a qual a chamada web 2.0 se constituiu" (D'ANDRÉA 2020: p.7) e buscam articular as dimensões técnicas, políticas e econômicas desse fenômeno.

Já a plataformização nada mais é que o modo de atuação e inserção das plataformas em diferentes níveis, esferas e camadas da vida social.

O termo "plataformização" é utilizado para se referir à emergência da plataforma como modelo econômico e infraestrutural dominante da web social, bem como às consequências da expansão das plataformas de mídias sociais em outros espaços online. (HELMOND 2019: p.61).

Assim, parece cada vez mais vital pensar a vida em sociedade enquanto uma experiência atravessada direta ou indiretamente por essas estruturas. Elas passam a configurar a chamada "sociedade de plataforma" (VAN DIJCK; POELL; WALL 2018). Não

\footnotetext{
${ }^{5}$ Veja-se, por exemplo, que os dados relativos aos padrões de comportamentos dos usuários do Facebook foram utilizados pela empresa para estabelecer estratégias de campanha eleitoral em diversos países.
} 
somente regulam nossas práticas online, como também centralizam boa parte das atividades do nosso dia a dia: Uber e Google Maps para deslocamentos urbanos; Spotify, Youtube e Deezer para consumo de músicas ou podcasts; Tinder, Grindr, Pitanga entre outros para encontros afetivo-sexuais; Airbnb, para aluguel temporário de quartos ou imóveis; Amazon para fazer compras; Skoob para organizar leituras; Netflix, Amazon Prime, HBO Go para o consumo de filmes e séries. Também é importante ressaltar que as empresas com atuação tradicional no espectro do entretenimento se adaptam a esse cenário, como nos mostram os dois últimos exemplos.

A situação se complica se pensamos o Facebook e as plataformas em seu domínio (Instagram, WhatsApp e Messenger), cujas funções ultrapassam supostos usos, ainda mais considerando o fluxo ininterrupto do tempo. Se de um lado, nossos smartphones vêm carregados de aplicativos e plataformas desde a fábrica, a cada vez que trocamos de modelo (muitas vezes sem possibilidade de desinstalação), de cidade, é preciso rever planos diretores, uma vez que os efeitos causados pela plataformização da vida social reformulam lógicas arquitetônicas e práticas sociais em escala infraestrutural. Nesse sentido:

A plataformização é definida como a penetração de infraestruturas, processos econômicos e estruturas governamentais das plataformas digitais em diferentes setores econômicos e esferas da vida. Ela também envolve a reorganização de práticas e imaginários culturais em torno dessas plataformas (POELL; NIEBORG; VAN DIJCK 2020: p.2).

Vale também pontuar que as múltiplas associações entre plataformas (e outras possíveis dimensões e instituições sociais online articuladas) resultam nos chamados "ecossistemas de plataformas" (VAN DIJCK 2013), enfatizando todo um conjunto relacional de elementos, práticas e tecnicidades heterogêneas que giram ou que são acionados por meio de usos individuais ou coletivos. Van Dijck (2013) ressalta que a organização das trocas sociais em "ecossistemas de conexão" se ampara numa lógica neoliberal, na qual "estratégias, competições e valores hierárquicos são intrinsecamente pertencentes” (VAN DIJCK 2013: p.20-21).

\section{Repensando etnografias e campos plataformizados}

Embora tenhamos um conjunto de pesquisas na área da comunicação que articularam com habilidade os estudos de plataforma ao modelo de trabalho etnográfico, como no caso da pesquisa desenvolvida por Guerra e d'Andréa (2020) relativa ao trabalho plataformizado dos serviços de entregas por trabalhadores da Uber, o contrário não ocorre de forma substancial, ainda que a proposta multissituada de Marcus (1995) tenha apostado 
nesse projeto. Ao se munir de estudos etnográficos multilocalizados, produzidos sob a perspectiva de um "sistema mundo", ou seja, da relação entre processos globais e contextos locais, Marcus sistematiza o panorama multissituado nos estudos antropológicos. O objetivo é atender uma demanda gerada pelas novas configurações interdisciplinares das áreas de estudo, sobretudo, pela influência dos estudos de mídia, apontada como uma das bases centrais a serem consideradas nas etnografias na segunda metade da década de 90, juntamente com os estudos de ciência e tecnologia (STS) e os estudos culturais. Entretanto, o autor adverte que a chave do projeto não está na tentativa de criar modelos holistas de funcionamento dos processos globais, mas de seguir as conexões parciais produzidas pelas relações entre os sujeitos e demais estruturas culturais através de seus múltiplos cruzamentos espaciais.

Embora a etnografia multissituada seja um exercício de mapeamento do terreno, seu objetivo não é ser uma representação holística, um retrato etnográfico do sistema mundo como uma totalidade. Ao contrário, reivindica que qualquer etnografia de formação cultural num sistemamundo seja também uma etnografia do sistema-mundo, não podendo ser entendida apenas em termos de uma mise-en-scéne de um convencional local isolado da pesquisa etnográfica, assumindo de fato sua formação cultural, produzida em múltiplos e diferentes locais, em vez de condições particulares de configurações dos sujeitos de estudo. (MARCUS 1995: p.99, tradução nossa)

Desse modo, a chave da etnografia multissituada se encontra nas "estratégias de seguir, literalmente, as supostas conexões, associações e relações [entre atores e estruturas sociais]" (MARCUS 1995: p.97, tradução nossa), premissa ressaltada por Segata (2011) ao reafirmar que "campo de pesquisa e objeto de pesquisa, a gente não encontra, a gente constrói” (SEGATA 2011: p.162).

Assim, na tentativa de visibilizar modos de articulação entre a teoria antropológica e os estudos de plataformização (da web e da vida social), a intenção desta seção é trazer alguns dos trabalhos feitos na área da comunicação para que possamos repensar nossas práticas etnográficas, não apenas realizadas em "contextos online", justamente por considerarmos os atravessamentos nem sempre visíveis das plataformas em nossos diversos campos de pesquisa. Tentaremos, portanto, a partir dos próximos exemplos, vislumbrar modos particulares de seguir as conexões, conforme indicado por Marcus, sem perder de vista os engendramentos entre processos do sistema-mundo e práticas localizadas, perspectiva que 
encontra um terreno fértil ao considerar os estudos de plataforma e o fenômeno da plataformização.

Comecemos por Elias Bitencourt (2019) que, a partir do estudo sobre a plataformização das práticas de exercício físico e do monitoramento dos sinais vitais dos consumidores da empresa Fitbit, nos apresenta formas singulares de relações sociais e construções corporais, resultantes tanto das affordances destes usuários quanto dos modelos de negócio adotados pela empresa. Para além das discussões relativas aos modos como as plataformas estão presentes nas práticas de atividades físicas cotidianas, o autor demonstra como as associações entre algoritmos, humanos e demais estruturas digitais são responsáveis pela coprodução de corpos, saberes, e até mesmo de uma nova espacialidade urbana. Assim, por meio de uma abordagem neomaterialista, percebemos formas com que corpos e algoritmos performam conjuntamente suas existências, partindo de um modelo relacional de constituição.

A tese intitulada "Smartbodies: corpo, tecnologias vestíveis e performatividade algorítmica - um estudo exploratório dos modos heurísticos de corporar na plataforma Fitbit" (BITENCOURT 2019) discorre sobre as formas com que vestíveis (geralmente no formato de relógios) apreendem os modos corporais diários de seus usuários, acabando por estabelecer "associações ainda mais próximas entre corpos, algoritmos e instituições, prometendo orientação individual e previsão de cenários futuros de acordo com os corpos de agora" (BITENCOURT 2019: p.19). A finalidade do instrumento é promover um trabalho de datificação do corpo, apresentando em tempo real (e periódico) uma mensuração de seus sinais vitais, assim como a elaboração de metas de exercícios, conforme os padrões de atividade, visando um aumento na performance física de seus usuários. Cabe também ao vestível a função de alerta frente a situações ou movimentos identificados como suspeitos ou irregulares. "De maneira simples, podemos dizer que os Smartbodies são híbridos cujas corporeidades e propriedades sociotécnicas resultam das associações entre gestos, hábitos, sensores, heurísticas, algoritmos e interfaces de visualização de dados" (BITENCOURT 2019: p.36). Em nível estrutural, a plataforma também promove uma série de relações sociais ao colocar usuários e prestadores de serviços em "diálogo", como veremos mais à frente.

Conforme exposto por Bitencourt, os vestíveis foram inicialmente planejados a fim de fornecer aos usuários informações precisas de desempenho físico. Diante da crescente popularização do produto, empresas começaram a investir em tecnologias de medição mais sofisticadas, compreendendo os processos de construção corporal por meio de estratégias mais dinâmicas e integradas de "leitura". Os comportamentos dos usuários não sendo apenas datificados numa lógica de "gamificação", mas visando também o planejamento de serviços 
de saúde locais ${ }^{6}$. "Os seguros de vida começaram a utilizá-lo para triar os clientes mais desejáveis; a medicina empregou-o no cálculo dos riscos relativos de manifestação de doenças cardiovasculares; os sujeitos estabeleceram novas percepções e práticas de dieta guiadas pelos números" (CZERNIAWSKI apud BITENCOURT 2019: p.18). Igualmente, outras empresas também estabelecem seus níveis de engajamento com diferentes setores públicos e privados: "Enquanto a Fitbit tem o seu foco deslocado aos programas corporativos de saúde no trabalho; a Apple ensaia parcerias com o setor médico, hospitais e instituições de pesquisa" (BITENCOURT 2019: p.16). "Segundo os documentos financeiros da marca, registra-se que em média 6.5 milhões de clientes atualmente compartilham dados corporais com planos de saúde e serviços corporativos que compõem seu ecossistema" (BITENCOURT 2019: p.20).

Por isso, é necessário entender que, quando falamos de um "ecossistema” produzido pelas plataformas, não apenas o caracterizamos digitalmente, considerando também uma rede infraestrutural que inclui inúmeras camadas e dimensões sociais. Para termos uma ideia mais precisa desse "ecossistema" e do tipo de trabalho oferecido por esses vestíveis, segue uma descrição realizada pelo autor:

Todas as vezes que você se movimenta em um espaço, nós registramos o seu padrão de deslocamento. Pela média do padrão de deslocamento de todas as pessoas no mesmo espaço, nós elaboramos uma "assinatura de movimento", isso é, a movimentação que melhor caracteriza um certo lugar. Através dela nosso sistema pode prever o tipo de atividade que você irá realizar quando chega em um estabelecimento novo, ou o tipo de atividade mais desempenhada em um espaço que você costuma frequentar. Isso ajuda nossos algoritmos a sugerirem o melhor exercício de acordo com a localidade ou diferenciar uma caminhada esportiva de um simples passeio nos seus ambientes favoritos. Essa tecnologia também pode ser aplicada para associar áreas próximas a uma mesma referência geográfica. Por exemplo, se sabemos que você está em casa, o GPS associa o deslocamento realizado no seu quarto aos movimentos produzidos em cômodos adjacentes (um quintal ou uma cozinha). Na próxima vez que você entrar em um desses ambientes, saberemos que você continua na sua residência. Nossos algoritmos também podem empregar os dados do seu batimento cardíaco associados à sua localização para construir uma avaliação emocional sobre uma determinada atividade realizada no

\footnotetext{
${ }^{6}$ Numa lógica em que, através dos exercícios propostos pelos algoritmos da plataforma, os usuários são encorajados a, cada vez mais, atingirem novos níveis de atividades.
} 
espaço. Se sabemos que você está em um teatro ou café, podemos usar a sua variação cardíaca para qualificar o serviço como bom ou ruim. Uma variação cardíaca alta durante uma peça, pode sugerir que você se mobilizou positivamente, por outro lado, uma frequência cardíaca elevada numa cafeteria pode indicar que o serviço é inadequado. Através das nossas APIs, essas ações podem ser automaticamente realizadas em aplicativos de terceiros. Isso significa que nossos parceiros podem ter acesso a essas informações e utilizá-las em seus sistemas de classificação de forma automática. Todos os dados extraídos são anonimizados e nós só coletamos o que é necessário para tornar a sua experiência Fitbit ainda mais fácil e significativa. (YUEN; PARK; LEE, apud BITENCOURT 2019: p.117)

Portanto, o que emerge desse processo é uma ontologia múltipla da carne "Para esses artefatos vestíveis, importa menos o que os corpos são (epistemologia) e mais o como eles se constroem (ontologia) nos fazeres diários” (BITENCOURT 2019: p.27). Para nós, antropólogos ou comunicólogos, não nos interessa saber o que necessariamente sejam os algoritmos, mas sim o que eles fazem (BUCHER 2018: p.10) e, principalmente, o que nós fazemos com e em relação a eles "Enquanto nós não podemos perguntar aos algoritmos da mesma forma que perguntamos aos humanos sobre suas crenças e valores, nós podemos tentar encontrar outros caminhos de fazê-los 'falar"' (BUCHER 2018: p.21, tradução nossa). Ao seguir esta ideia, Bucher irá nomear essa prática de "tecnografia". Segundo ela "Tecnografia, do modo como uso, é o modo de descrever e observar os trabalhos da tecnologia de forma a examinar a interação entre um diverso conjunto de atores (humanos e não-humanos)" (BUCHER 2018: p.21, tradução nossa).

No Brasil, o serviço ainda não possui o mesmo grau de integração com outros espaços e serviços, como visto na descrição acima, por exemplo. Porém, as possibilidades etnográficas trazidas no trabalho de Bitencourt são inúmeras, pensando nas mediações entre os atores e tecnicidades envolvidas, tendo em vista a plataformização dessa tecnologia e, principalmente, no que diz respeito aos modos performativos de construção, tanto dos corpos quanto dos algoritmos, que também são performados e co-constituídos. É bastante interessante ouvir os relatos de Bitencourt acerca dos dados etnográficos por trás de sua pesquisa, que nos apresentam modos particulares desse "convívio algoritmo", desde pessoas que refizeram as atividades diárias ao descobrirem algum tipo de imprevisto na mensuração pelo vestível, àquelas que passaram a desempenhar novas práticas ou performances sexuais a fim de transformar a leitura algorítmica sobre si mesmo. É através deste processo de "tornar-se com" (HARAWAY 2011: p.16) que nosso interesse principal se estabelece ao 
falarmos de etnografias "plataformizadas", cujas tecnicidades são mais que tecnologias de informação, consituindo-se enquanto espécies companheiras digitais (LUPTON 2016). Na tentativa de compreensão da qualidade destas "companhias", identificamos as particularidades nas relações de aprendizado e afeto construídos entre humanos, algoritmos e demais estruturas digitais, cujas trocas estão para além de algo propriamente estável, mas ocorrem em termos de negociação. É também neste sentido que o trabalho apresentado por Elias Bitencourt se vincula ao projeto multissituado de Marcus, ao perseguir os trânsitos entre as práticas locais individuais e coletivas em confluência aos sistemas multilocalizados de operação das estruturas digitais da empresa Fitbit.

A distinção entre os mundos da vida dos sujeitos e os do sistema não se mantém, e o objetivo da etnografia dentro do alcance de sua perspectiva sempre local e próxima é o de descobrir novos caminhos de conexão e associação pelos quais as preocupações etnográficas tradicionais com agência, símbolos, e as práticas cotidianas podem continuar a ser expressas em uma tela espacial configurada de forma diferente. (MARCUS 1995: p.98, tradução nossa)

Noutro sentido, a tese de Bitencourt também contribui para repensar uma antropologia do corpo. Esta, que já vem tomando caminhos bastante férteis, sobretudo com os desdobramentos neomaterialistas de Mol (2002) e tecnopolíticos de Donna Haraway (2008; 2009), é frequentemente retomada nos estudos de plataforma. No corpo, as plataformas adquirem seus sentidos e seus fins, uma vez que toda experiência plataformizada é também uma prática de transformação de si a níveis físicos e psíquicos, tal como uma reconfiguração das relações entre os corpos em nível social. Ao se desdobrarem sobre os diferentes marcadores sociais, as plataformas fazem deles parte fundante de seus modelos de operação. A partir das atuações performadas nos e através dos corpos, acabamos por nos questionar: que corpos são esses? Como esses fluxos afetam e são afetados pelos corpos dos/aos quais se co-constituem? Quais os efeitos dessa plataformização encarnada na vida social? Como a plataformização reorganiza os sentidos e o contato com os diversos Outros? Se o corpo é um projeto cultural em contínuo processo de construção e afetação, já que "ter um corpo é aprender a ser afetado" (DESPRET 2011: p.56), as práticas responsáveis por sua produção sempre acompanharam processos emergentes de constituição do real. Por isso, é tão indispensável nestes estudos pensar nos modos plataformizados de composição dos corpos, tais quais as negociações envolvidas entre os usuários em relação aos modelos de negócio e governança adotados por essas empresas. 
Por isso, é bastante atraente pensar na forma com que plataformas colocam em circulação e mediação diferentes relações entre usuários. Num jogo de "antropologia especulativa" (SAER 1997), Elias Bitencourt, com base na sua experiência como cliente da companhia Fitbit, simula o funcionamento dos vestíveis num capítulo de etnografia ficcional. Ao criar uma narrativa fictícia sobre a relação de Ulisses e Percival, dois homens na terceira idade que são apresentados por seus vestíveis por realizarem trajetos semelhantes numa pequena parte da cidade, a pesquisa mostra como esse tipo de convivência permite aos usuários experimentarem uma melhora em seus níveis de atividade física. A pulseira da empresa coloca em comunicação o desempenho de ambos os personagens e realiza uma espécie de relação mediada. Tanto Ulisses como Percival, desde que receberam o "convite" para acompanharem os resultados um do outro, numa espécie de "solicitação de amizade" do Facebook, realizam práticas de atividade em comum. A proposta é trazer uma melhora no desempenho e no nível de atividade dos dois ao trabalharem em conjunto. Ao praticar seus exercícios em dupla, ainda que separados fisicamente, assumem um compromisso entre si, estabelecendo novas metas de exercício à medida que a afinidade entre os dois se estreita. Da mesma maneira, podemos pensar nos diferentes modos de gestão social executados pelas plataformas que usamos diariamente: Uber, iFood, Amazon, Tinder. De que forma tais ambiências reorganizam a circulação dos corpos e afetos, assim como cristalizam relações sociais a nível estrutural?

Jessalynn Keller, por sua vez, em seu artigo intitulado "Oh, She's a tumblr feminist", de 2019, apresenta alguns resultados dos estudos feitos entre 2014 e 2015, com jovens de 14 a 19 anos, residentes do Canadá, Reino Unido e Estados Unidos, que participam de redes feministas online. $\mathrm{O}$ intuito da pesquisa foi analisar como diferentes plataformas podem ser "palcos" de atuações políticas por essas jovens e, de que forma, esse trabalho de engajamento é compreendido por essas ativistas ao considerar as apropriações que fazem destes espaços (Facebook, Twitter e Tumblr), levando em conta suas particularidades. A autora se questiona: a) por que as garotas estão usando determinadas plataformas para o ativismo feminista? b) como certas plataformas oportunizam diferentes formas de envolvimento de jovens com a política feminista? c) como isso pode moldar os tipos de questões feministas e políticas tornadas possíveis e excluídas por algumas plataformas de mídia social? (KELLER 2019: p.1). Embora Keller seja uma pesquisadora do campo da comunicação, assim como Bitencourt, seu trabalho propõe um diálogo intimamente (e assumidamente) atravessado pela prática e teoria etnográfica, considerando seu exercício de aproximação, inserção e comprometimento nas redes analisadas.

Uma das etapas de análise se debruça sobre a "vernaculidade" desses ambientes, noção bastante presente nesse campo de investigação. Segundo a autora, o conceito "chama a atenção para os gêneros de comunicação únicos que se desenvolvem de acordo com as 
possibilidades de plataforma" (KELLER 2019: p.2, tradução nossa), que também leva em conta "os conflitos de interesses de usuários, empresas, anunciantes e legisladores" (GILLESPIE 2010 apud KELLER 2019: p.2, tradução nossa). Em alguma medida, a noção de "vernaculidade das plataformas" corresponde à dimensão da "tradução" posta por Marcus (1995) como aspecto central no trabalho etnográfico multissituado:

Ainda, o que permanece essencial para uma pesquisa multissituada é a função da tradução de um idioma ou idioma cultural para outro. Esta função é aprimorada, uma vez que não é mais praticada no quadro primário dualístico "eles-nós" da etnografia convencional, mas requer consideravelmente mais nuances e delineamentos, pois a prática da tradução conecta os vários locais que a pesquisa explora ao longo de fraturas inesperadas e até dissonantes de localização social (MARCUS 1995: p.100, tradução nossa).

Para Keller, a vernaculidade não somente diz respeito à condição gramatical, mas também ao nível das affordances praticadas por suas interlocutoras, ou seja, aos modos com que percebem suas atuações em cada um desses espaços. O que não contradiz a ideia de tradução levantada por Marcus, mas se coloca como um novo desdobramento de sua proposta. As affordances, portanto, "tornam-se tanto parte das experiências dos usuários e percepções das tecnologias quanto das próprias tecnologias” (BUCHER; HELMOND apud KELLER 2020: p.4, tradução nossa).

Seguindo a percepção das ativistas com quem trabalhou, Keller indica possíveis limites e potencialidades para cada uma das plataformas onde as atuações políticas são performadas. Enquanto o Facebook é visto como um ambiente propício a diálogos de maior envergadura, por contar com redes de amigos e familiares mais próximos, ele também se instaura como lugar de insegurança para a exposição de relatos mais íntimos e pessoais, justamente pela presença destas redes de parentesco. Assim, a estratégia utilizada nestes espaços é a de compartilhar e discutir experiências de terceiras. As jovens também levam em conta os efeitos provocados pela impossibilidade do anonimato neste ambiente, que podem culminar em ameaças ou represálias mais individualizadas, ao contrário do Twitter e do Tumblr, que oferecem a possibilidade de anonimato, embora também existam particularidades entre eles. Na primeira, as hashtags favorecem e facilitam a organização temática, e por isso promovem conexões rápidas entre usuárias dispersas geograficamente, ao mesmo tempo que a plataforma se configura enquanto um ambiente muito acirrado politicamente por concentrar e agregar diversas posições teórico-políticas, sendo, inclusive, marcada pela qualidade controversa de suas discussões. Por isso, torna-se um espaço de 
intensa perseguição e assédio a diversas frentes de mobilização social. No Tumblr, por sua vez, além do apelo estético, considerado muito atrativo e vantajoso para a causa feminista, essas meninas desfrutam não só de um anonimato, quanto de ferramentas de controle sobre as interações com o conteúdo político postado, facilitando a forma de gerenciamento dos "efeitos" de suas práticas. Além disso, pelo fato do Tumblr não ter como prioridade as ferramentas de busca, tem-se uma sensação de maior liberdade (KELLER 2019: p.8) que elas relacionam à privacidade social. Consequentemente, esta última é percebida por essas jovens como a plataforma mais adequada as suas estratégias de luta.

Portanto, uma etnografia virtual que não considere as estruturas e as dimensões de plataformização, tende a ignorar os efeitos reais dessas experiências, suprimindo escalas etnográficas (MARCUS 1995) importantes em seus projetos de pesquisa. Pois, são através das dinâmicas marcadamente plataformizadas que muitos dos nossos fenômenos ganham a "carne" que, efetivamente, sustenta o esqueleto do campo etnográfico ao qual atravessamos. A partir de uma perspectiva multilocal de pesquisa, que se alinhe aos processos da plataformização e aos estudos de plataforma, podemos ter acesso às diversas engrenagens que reatualizam as práticas e as arquiteturas da vida social. Por isso "Assim como este modo [multissituado] investiga e constrói etnograficamente os mundos da vida de sujeitos situados de várias maneiras, também constrói etnograficamente aspectos do próprio sistema por meio das associações e conexões que sugere entre os locais” (MARCUS 1995: p.95, tradução nossa).

De outras formas, caminho por todas essas questões em minha pesquisa atual, relativa à busca de novos amores por casais não-monogâmicos em comunidades do Facebook, o que venho a denominar de "projetos poliamorosos". Ainda que o poliamor tenha surgido enquanto um movimento organizado durante as décadas de 60 e 70 em meio às manifestações pela igualdade e liberdade sexual nos EUA, será com a popularização da internet que este fenômeno atingirá proporções ainda maiores e, definitivamente, se consolidará como uma prática/ética social reconhecida. No Brasil, os primeiros grupos poliamoristas organizados surgem em contexto estritamente online em meados da primeira década dos anos 2000 e serão responsáveis por tecer críticas à estrutura social hetero e mononormativa. Assim, como novos desdobramentos dessa prática, as comunidades virtuais serão mais que locais de discussão e de "experiências emancipatórias" (SILVÉRIO 2018: p.197), tornando-se também ambientes propícios às buscas afetivas, ou seja, lugares convenientes para a procura de novos parceiros. Sendo estes, espaços seguros para a descoberta de uma ética poliamorista/não-monogâmica, questões que se colocam de formas muito intensas não somente para não-monos de "primeira viagem". Tais inseguranças ocorrem, como muito bem apontado pelas etnografias já feitas sobre a temática, porque se decidir pela não-monogamia em vias políticas, faz com que repensemos todo tipo de relações 
sociais, e não somente aquelas às quais tratamos por afetivo-sexuais. O modo como o amor, o ciúme, o afeto, a amizade e a estrutura familiar são vistas (para citar só algumas dessas esferas) passa a adquirir novos contornos ao se iniciar um relacionamento ou assumir uma postura política que negue a monogamia e a heteronormatividade compulsória. A nãomonogamia enquanto prática ética contra hegemônica, que se proponha a romper as premissas colonialistas dos afetos, torna-se uma conduta reordenadora da vida social para esses sujeitos.

Assim, se as experiências desses grupos são, predominantemente, vividas nas e através das plataformas, como pensar o que significa amar poliafetivamente? Assumir uma postura ética e política não monocentrada? Buscar um amor através desses espaços? Elas (as plataformas) ressignificam os sentidos e as práticas afetivas dos envolvidos? Como as redes textuais poliamorosas são produzidas ao atravessarem múltiplas plataformas e de que forma elas podem impactar nas práticas e nos desejos destes sujeitos? Eu, como pessoa não-mono, não consigo não atribuir às plataformas um papel central para a construção das minhas experiências afetivas, considerando a atuação destes espaços para a modulação de um "eu" enquanto "projeto social em curso", noção utilizada por Appadurai (2004: 15) ao pensar o papel das mídias e das redes para a configuração dos coletivos sociais e dos modos particulares de construção de si num mundo global. Por isso, para mim, refletir sobre as plataformas é também pensar nos modos como uma vida é vivida, assim como novos mundos podem ser possíveis.

\section{Considerações Finais}

A ideia deste texto surgiu em meio à Iniciação Científica $\mathrm{O}$ antropólogo no campo e na rede: o fazer etnográfico em pesquisas de gênero e sexualidade, encerrada em meados de 2017 e desenvolvida, principalmente, pelo incômodo de se pensar a intransponibilidade das categorias etnográficas tradicionais às pesquisas antropológicas em contextos online. Se naquele momento vimos um baixo impacto das discussões trazidas pelas etnografias virtuais nas ementas dos cursos em Antropologia Social, isso precisou ser revisto, sobretudo, após as eleições brasileiras de 2018, cujo cenário tornou impossível ignorar os efeitos da plataformização na/da vida social. Foi por meio da minha inserção no programa de Pósgraduação em Comunicação Social e no contato que tive com os estudos de plataforma que pude repensar algumas das perguntas feitas nos anos anteriores, ainda na graduação em Antropologia Social.

A “plataformização da web” refere-se aos processos de intercâmbio de dados entre as diversas plataformas online e às remodelagens infraestruturais adotadas pelas grandes empresas globais. Este processo se inicia a partir da web 2.0, ponto de refiguração da 
estrutura digital que se propôs dar um novo sentido à internet, o que nos levou a um cenário de trabalho algoritmo individualizado, cujo foco é saber, produzir e alimentar os desejos pessoais de seus usuários. Essa empreitada foi e é liderada, sobretudo, pelo Facebook, que além de impor um modelo de recursos (o botão "curtir" como o mais clássico deles) e estéticas às demais plataformas e ambientes online, também vem tentando incorporar boa parte da estrutura da web para dentro dos seus territórios. À medida que as plataformas e suas lógicas de funcionamento passam a atravessar diferentes níveis e esferas da vida coletiva, temos a chamada "plataformização da vida social", que acaba por reconfigurar as experiências e os sentidos sociais, produzindo o que Van Dijck, Poell e Wall (2018) denominam de "sociedade de plataforma". Esta, habitada por inúmeros Outros, pensados enquanto "espécies companheiras digitais" (LUPTON 2016), não somente trabalham conosco através de inúmeras associações, como também fazem parte da co-constituição das dimensões afetivas, corporais e estruturais da vida humana (mas não somente).

Embora a ideia de "etnografia multissituada" trazida por Marcus (1995) seja útil para pensar a maneira como seguimos os fios que atravessam nossas pesquisas, precisamos ir além, ao entender as dinâmicas impostas pela estrutura de plataformização dos ambientes virtuais, que requerem noções mais situadas de presença, espaço, linguagem, observação, autoridade etnográfica, participação, conexão, campo etnográfico, alteridade, corpo, "estar lá”, afeto, dentre tantas. Por isso, este artigo apresenta-se como uma ponte para o projeto multilocal de Marcus ao ser vinculado às esferas de trabalho etnográfico plataformizado. Além disso, os layouts e recursos presentes nestes territórios se mostram bastante voláteis, o que acaba gerando uma insegurança no pesquisador ao estudar tais materialidades, mas também pode ser visto enquanto potencialidade de análise, considerando os modos contínuos de reordenamento dos sentidos, práticas, afetos, corpos e relações sociais instauradas por esses espaços. Assim, o objetivo deste artigo foi demonstrar como os estudos de plataforma e as práticas etnográficas devem caminhar juntas para que possamos ter uma melhor compreensão dos processos de mudança social. E que, se o passo de largada já foi dado na área da comunicação, como levantado no texto, o mesmo precisa ser feito na antropologia.

Assim, ao friccionarmos a ideia de etnografia multissituada aos estudos de plataformas, podemos nos atentar às especificidades desses espaços e de que maneira eles nos dizem, ou podem nos dizer, acerca dos modos que regulam, atravessam ou modulam os diferentes sociais que habitamos, sejam online ou não. Da mesma maneira, nos apontam para as qualidades das performances que fazemos ao nos relacionarmos com essas novas materialidades e entes digitais.

\section{Referências bibliográficas}


APPADURAI, Arjun. (2004). Dimensões culturais da globalização: a modernidade sem peias. Lisboa: Teorema.

ÁVILA, Simone. (2014). FTM, transhomem, homem trans, trans, homem: A emergência das transmasculinidades no Brasil contemporâneo. Tese de Doutorado - Ciências Humanas. Florianópolis: UFSC.

BARBOSA, Marcela. (2014). A prática crossdresser na blogosfera: um estudo baseado em análise de blogs crossdressers. Dissertação de Mestrado - Antropologia Social. Goiânia: Universidade Federal de Goiás.

BITENCOURT, Elias. (2019). Smartbodies: corpo, tecnologias vestíveis e performatividade algorítmica: um estudo exploratório dos modos heurísticos de corporar na plataforma Fitbit. Tese de Doutorado - Comunicação e Cultura. Salvador: UFBA.

BRUNO, Fernanda. (2019). Tecnopolítica, racionalidade algorítmica e mundo como laboratório. Entrevista para o site Digilab. Disponível em: https://digilabour.com.br/2019/10/25/tecnopolitica-racionalidade-algoritmica-emundo-como-laboratorio-entrevista-com-fernanda-bruno/. Acesso em: 26 de set. de 2020.

BUCHER, Taina. (2018). If... then: Algorithmic power and politics. Londres: Oxford University Press. DOI: 10.1093/oso/9780190493028.001.0001.

D'ANDRÉA, Carlos. (2020). Pesquisando plataformas online: conceitos e métodos. Salvador: EDUFBA.

DANTAS, Jenniffer. (2011). Sexo sobre rodas: vivências e discursos da sexualidade de homens cadeirantes. Dissertação de Mestrado - Sociologia. Fortaleza: UFC.

FACIOLI, Lara. (2013). Conectadas: uma análise de práticas de ajuda-mútua feminina na era das mídias digitais. Dissertação de Mestrado - Sociologia. São Carlos: UFSCar.

DESPRET, Vinciane. (2011). Os dispositivos experimentais. (Traduzido por carlos Marconi). In. Fractal: Revista de Psicologia, v. 23, n. 1, p. 43-58.

FREITAS, Fátima. (2011). Sexualidades: prazeres, poderes e redes sociais. In. Anais do II Seminário de pesquisa da Faculdade de Ciências Sociais. Goiânia: UFG.

GUERRA, Ana; D'ANDRÉA, Carlos. (2020). Dimensões algorítmicas do trabalho plataformizado: cartografando o preço dinâmico da Uber. Brasília: E-COMPÓS (no prelo). Disponível em https://www.e-compos.org.br/e-compos/article/view/2046. Acesso em 26 de set. de 2020. doi: https://doi.org/10.30962/ec.2046.

GUIMARÃES JÚNIOR, Mário. (2000). O ciberespaço como cenário para as ciências sociais. In. Revista Ilha, n.1, Florianópolis. p. 139-154.

HARAWAY, Donna. (2008). When species meet. Minneapolis: University of Minnesota Press. 
HARAWAY, Donna. (2009). Manifesto Ciborgue: Ciência, tecnologia e feminismosocialista no final do século XX. In. Tadeu, Tomaz (org.) Antropologia do ciborgue: as vertigens do pós-humano. Belo Horizonte: Autêntica.

HELMOND, Anne. (2019). A Plataformização da Web. (Traduzido por Tiago Salgado) In: OMENA, Janna (Org.). Métodos Digitais: Teoria-Prática-Crítica. Lisboa: Livros ICNOVA, p. 49-73.

JENKINS, Henry. (2006). Convergence culture: where old and new media collide. New York: New York University Press.

KELLER, Jessalynn. (2019).“Oh, She's a Tumblr Feminist”: Exploring the Platform Vernacular of Girls' Social Media Feminisms. Sage Journals: Social Media + Society, v. 5, n. 3, p.1-11. doi:: 10.1177/2056305119867442.

LEWGOY, Bernardo. (2009). A invenção da (ciber)cultura: virtualização, aura e práticas etnográficas pós-tradicionais no ciberespaço. In. Revista Civitas, v. 9, n. 2, Porto Alegre, p. 185-196.

LUPTON, Deborah. (2016). Digital companion species and eating data: implications for theorising digital data-human assemblages. Big Data \& Society, v. 3, n. 1. doi: $10.1177 / 2053951715619947$.

MARCUS, George. (1995). Ethnography in/of the World System: the emergence of multisited ethnography. In: Annual Review of Anthropology, v. 24, Palo Alto, California, p. 95-117.

MOL, Annemarie. (2002). The Body Multiple: ontology in medical practice. Durham \& London: Duke University Press.

POELL, Thomas; NIEBORG, David; DIJCK, José van. (2020). Plataformização. Fronteiras estudos midiáticos, São Leopoldo (RS), v. 22, n. 1, p. 2-10. doi: 10.4013/fem.2020.221.01.

RIFIOTIS, Theophilos. (2016). Antropologia no ciberespaço como repovoamento e explicação. In. Anais RBCS v. 31, n. 90. p. 85-99. doi: http//dx.doi.org/10.17666/31908598/2016

SAER, José. (1997). El concepto de ficción. Buenos Aires: Espasa Calpe.

SEGATA, Jean. (2008). Entre sujeitos: o ciberespaço e o ANT. In. Anais II Simpósio Nacional de Pesquisadores em Cibercultura, São Paulo.

SEGATA, Jean. (2011). Uma dose de poesia e experiência: ou o que atravessa o caminho da pesquisa nas humanidades. Revista Caminhos, v. 1, Rio do Sul, p. 135-154.

SILVA, Daniela. (2004). Do outro lado do espelho: anorexia e bulimia para além da imagem - uma etnografia virtual. Dissertação de Mestrado - Antropologia Social. Campinas: Universidade Estadual de Campinas.

SILVA, Tarcízio et al. (2020). APIs de Visão Computacional: investigando mediações algorítmicas a partir de estudo de bancos de imagens. Logos, v. 27, n. 1, p. 25-54. 
SILVÉRIO, Maria Silva. (2018). Eu, tu ilus: poliamor e não-monogamias consensuais. Tese de Doutorado - Antropologia Social. Instituto Universitário de Lisboa ISCTE IUL: Lisboa.

VAN DIJCK, José. (2013). The culture of connectivity. New York: Oxford University Press. VAN DIJCK, José; POELL, Thomas; WALL, Martijn. (2018). The platform society: public values in a connectie world. Londres: Oxford Press. doi: 10.1093/oso/9780190889760.001.0001.

VENCATO, Ana Paula. (2015). Entre "reais" e "virtuais": noções sobre risco e verdade em um clube brasileiro para crossdressers. In. Cadernos Pagu, v. 4, p. 367-390. doi: https://doi.org/10.1590/1809-4449201500440367.

sobre o autor

\section{Ítalo Vinicius Gonçalves}

É graduado em Antropologia Social e mestrando em

Comunicação Social, ambos pela Universidade Federal de Minas Gerais.

Recebido em 30/09/2020

Aceito para publicação em 26/12/2020 